\title{
Promoting articulated action from diverse stakeholders in response to public policy scenarios: a case analysis of the use of 'scenario improvisation' method
}

\author{
George Cairns ${ }^{1}+$
}

Centre for Sustainable Organisations and Work, RMIT University, Melbourne, Australia

Email: george.cairns@qut.edu.au

Phone: +61(0) 416514560

\section{George Wright ${ }^{2}$}

Strathclyde Business School, University of Strathclyde, Glasgow, UK

Email: george.wright@strath.ac.uk

Phone: +44(0)7534920472

\section{Peter Fairbrother ${ }^{3}$}

Centre for Sustainable Organisations and Work, RMIT University, Melbourne, Australia Email: peter.fairbrother@rmit.edu.au

Phone: +61 (0) 399251505 or 99252500

+ Corresponding author

${ }^{1}$ George Cairns now works at QUT Business School, Queensland University of Technology, 2 George Street, PO Box 2434, Brisbane, QLD 4001, Australia

2 Strathclyde Business School, University of Strathclyde, Livingstone Tower, 26

Richmond Street, Glasgow G1 1XH, UK

${ }^{3}$ Centre for Sustainable Organisations and Work, RMIT University, Building 80, 445 Swanston Street, Melbourne, VIC 3000, Australia 


\title{
Promoting articulated action from diverse stakeholders in response to public policy scenarios: a case analysis of the use of 'scenario improvisation' method
}

\begin{abstract}
In this paper we present a novel application of scenario methods to engage a diverse constituency of senior stakeholders, with limited time availability, in debate to inform planning and policy development. Our case study project explores post-carbon futures for the Latrobe Valley region of the Australian state of Victoria. Our approach involved initial deductive development of two 'extreme scenarios' by a multi-disciplinary research team, based upon an extensive research program. Over four workshops with the stakeholder constituency, these initial scenarios were discussed, challenged, refined and expanded through an inductive process, whereby participants took 'ownership' of a final set of three scenarios. These were both comfortable and challenging to them. The outcomes of this process subsequently informed public policy development for the region. Whilst this process did not follow a single extant structured, multi-stage scenario approach, neither was it devoid of form. Here, we seek to theorise and codify elements of our process - which we term 'scenario improvisation' - such that others may adopt it.
\end{abstract}

Keywords: scenario method, stakeholders, improvisation, reframing, policy

\section{Introduction}

In this paper, we discuss a novel approach to the application of scenario methods as part of a major project to explore post-carbon futures for the Latrobe Valley region of the Australian state of Victoria. Specifically, we discuss an application that combined both deductive and inductive approaches to scenario development, that involved extensive in-depth research by a multi-disciplinary academic team to inform initial scenario development, and that then engaged time-poor senior decision-makers from the region in intensive collaborative scenario workshops. In these workshops, the initial scenario narratives were challenged, refined and expanded. In particular, the research team actively sought to reframe problematic issues identified by participants, to present these back as potential opportunities for the future. However, this reframing had to be credible and relevant to the stakeholders if it was to be purposeful to them. The outcome of the scenario exercise was a set of three 'extreme scenarios' for diverse futures for the region, for which participants took 'ownership', along with an agreed action list generated by participants. These documents informed subsequent policy and planning processes by participants and their agencies and organizations.

The project involved a broad range of stakeholder groups; Federal, State and local governments, various industry groups with diverse and sometimes conflicting needs and priorities, and representatives of local community and labour groups, again with values and desires that were not clearly aligned with each other. The 
representatives of these various bodies who participated in the scenario workshops were senior individuals, with limited time availability and with whom it was difficult to coordinate diaries. In response, the scenario method that we employed was designed to facilitate deep engagement over the project, but within individual short timeavailabilities. Our method did not follow any single, established, structured, multi-stage scenario approach $(1,2,3)$, but neither was it devoid of form. Rather, it drew upon basic elements of various extant approaches, both deductive and inductive, in a process that we term 'scenario improvisation' (SI). Methodological elements of our approach were chosen and assembled to suit the needs of engagement with key stakeholders from the region, valuing their limited availability but yet providing challenge to their expert, but perhaps bounded knowledge of the region. The region (as defined by the Commonwealth and Victorian State governments for the project) comprises three local councils - Baw Baw, Latrobe City, and Wellington - and is part of Gippsland (so defined for economic development purposes), an area to the east of Melbourne, the capital of the State of Victoria. Three further councils make up Gippsland, namely; East Gippsland, South Gippsland and Bass Coast. The total population of Gippsland was 255,718 in 2011 (ABS 2012) and the economy is based on four major resources: coal, oil and gas, forestry and agriculture [4].

The outcome of the full research project was a Final Report (4) that identified opportunities for and barriers to economic revitalisation, and presented key considerations and priorities to inform public policy. Here, we present, analyse and discuss the process by which initial scenarios were developed solely within the research team, then explored, refined and extended collaboratively with the stakeholders and, finally, incorporated into the narrative to inform the Final Report. We codify key elements of the operational framework of 'scenario improvisation' for subsequent scenario inquiry by others. We illustrate how this approach has the potential to overcome the issue raised by Rickards et al., (5, p.654), that "... there often seems to be a disconnect between the anticipation that scenario planning will 'inform' - that is, provide an evidence base for - decision making in the near term, and the realisation that the process has limited discernible impact on subsequent decisions".

\section{Contextual background of the project and its aims}

The key aim of the full Federal Government funded research project was to examine the socio-economic and political dimensions to support investment opportunities and to identify prospective local economic developments and thus potential job growth in the Latrobe Valley region of Gippsland. The population of the Latrobe Valley region in 2011 was 156,704, in an area where resource extraction and use; coal, forestry, agriculture (and related production), oil and gas; underpinned the local economy. While the economy was primarily resource-based, in terms of employment there was a growing service sector along with a large defence facility and a small (but expanding) aero industry. As elsewhere in Australia, employment in the health and education services had increased over the previous decade. However, the 
region was seen to be facing an inevitable period of structural adjustment in a global context that was trending towards a post-carbon future.

The focus of the scenario workshops was to explore options for sustainable futures for the region in the face of an unsustainable present. In the local context, over 80 per cent of Victoria's electricity requirements were sourced from coal-fired generators in this region, fuelled by a substantial local brown coal (lignite) extraction industry. This coal-fired generation industry was seen as unsustainable in the longer term, and the prospective closure of one or more of the four power generators and, potentially, coalmines would bring specific challenges to the Latrobe Valley and the wider Gippsland region.

\section{INSERT MAP 1 ABOUT HERE}

In addition to the potential loss of key industry sectors driven by environmental concerns, the region was also seen as exposed to potential climate change impacts bushfire, coastal inundation, and so forth. It would, therefore, be affected both directly by climate events and indirectly by related policies, including the carbon-pricing scheme of the then Labor Federal government. In January 2012, the Commonwealth Department of Regional Australia, Local Government, Arts and Sport commissioned the Centre for Sustainable Organisations and Work to examine the opportunities and threats associated with these potential and seemingly likely changes (no longer an immediate prospect with the election of a conservative federal government in 2013 and the termination of carbon pricing arrangements).

\section{Scenario methods, stakeholder engagement and impacts on policy and planning}

Scenario methods have proven popular over decades as means both for single organizations or industry sectors and for diverse organizational groups to engage with complex and ambiguous issues for which there are no predictable outcomes (e.g. 6, 7) and to seek innovative change (8). However, in relation to such broad issues in the societal domain, it is not clear whether previous use of scenario methods can be clearly shown to have direct impact in relation to public policy generation (e.g. 5, 9, 10). Recently, scenario methods have been subject to extensive debate and discussion, notably in a special issue of Technological Forecasting \& Social Change (11) in which recent developments were presented, but where critical issues and problems were also addressed. Many of these have been subject to ongoing discussion in the literature, including: how to involve time-poor senior members and decision-makers $(12,13)$, how to address individual differences in cognitive style during scenario workshops $(14,15$, 16), how to assess the success or failure of scenario projects with different degrees of stakeholder participation $(17,18,19)$ and, of particular concern in this project, how to ensure a link between scenario building and public policy development $(5,9,10)$. These issues were of particular concern to us, in seeking to elicit commitment to action by our senior decision makers in order to realise a desired future (20). 
Probably the most widely known and used scenario approach in the practice arena, developed from the work of Shell in the 1960s (cf. 21), draws upon intuitive logics-based (IL) 'forward-chaining', where scenarios are constructed through building chains of cause-effect or chronological linkage, based upon a structured analysis of the present - such as through the use of PEST analysis or its derivatives (22). This approach has been critiqued as being open to 'heuristic bias' (23), whereby workshop participants may assign greater prominence to imagined sequences of events - based on current knowledge and thinking - than probabilistic calculation would support.

The IL method requires the involved stakeholders to be the developers of the scenarios, implicitly learning the scenario method and undertaking several iterations of driving-force generation, interpretation, and analysis. This frequently takes place over a substantial period of time, multiple stages of analysis and involves substantial time commitment by participants $(1,2,24)$. Bowman et al. (17) discuss the efficacy of involvement of stakeholders in a time-rich inductive scenario building process involving deep engagement in strategic conversation and trust building amongst scenario workshop participants. They argue that this extended process enables partisan, micropolitical agendas to be dissipated. The positive outcomes of a time-rich approach are evidenced in the renowned Mont Fleur scenario program (25) to explore potential futures for post-apartheid South Africa. However, the process may be compressed into as little as 24 hours but such limited exercises may elicit only a broader understanding of a problem issue rather than action in response to it (2, p. 12). Cairns et al. (26) outline how such a 24-hour scenario workshop produced seeming shared understanding, agreement and commitment to act amongst diverse organizational members, but with no evident follow up over time from participants who were not senior decision- and policy-makers.

An alternative scenario method that is designed to engage multiple stakeholders with diverse and conflicting values and beliefs, but with a focus on achieving some form of 'common good' for the future is a 'critical scenario method' (CSM) $(2,28)$. CSM is grounded in Aristotelian philosophy and his intellectual virtue of phronēsis, or moral/ethical thinking to inform action for the 'good of man' (sic). CSM requires explicit consideration of issues of power and politics and debate on who will be winners and who losers within different future scenarios (cf. 28). It is an augmentation of the basic IL scenario method and, as such, raises a similar requirement of extensive commitment and involvement from workshop participants.

Notwithstanding the positive attributes of time-rich scenario development, Healey and Hodgkinson (29) point to the danger that such extensive engagement by involved and affected stakeholders may lead to a strengthening of existing mindsets rather than present a challenge to these. In order to overcome such 'strategic myopia', van der Heijden (30) advocates involving 'remarkable people' in the scenario development process - individuals from outside the problem context who can bring challenging insights and ideas to the table. However, this is likely to add further time commitments to an already-time-rich IL process. 
In contrast to the inductive approach, Bowman et al. (17) discuss the alternative deductive approach, whereby pre-constructed scenario narratives are presented to the involved stakeholders. Drawing on the notion of 'backcasting' $(18,31)$, these narratives are then subject to critical discussion in order to test the logics of causality and chronology. In principle, this approach should reduce the time commitment of workshop participants, but Bowman et al. (17) present a negative report on such an exercise, in which participants sought to identify and embed their own organizational politics, events and values into slight variations of the pre-constructed scenarios, using them as 'checklists' rather than challenges.

In another variant, Wright and Goodwin (32) discuss the potential of a 'backwards logic' method (BLM) of scenario analysis. Whilst this draws upon elements of backcasting, it engages involved stakeholders in constructing 'extreme scenarios' for the future (non-) achievement of key organisational objectives. In contrast to the IL approach; where scenarios are built up inductively from analysis of extant 'driving forces' (24); BLM involves deductive analysis of plausible, but extreme, futures. Where the IL method can lead to a reinforcing of existing mental models rather than their challenge (29), the backwards logic approach requires participants to develop the logic of a presented 'extreme' scenario through intuitive effect-cause analysis (cf. 33).

In the project discussed here, we sought to build on the strengths of the inductive IL approach to scenario building, whilst considering the potential of the BLM approach. Nonetheless, whilst there is evidence of successful use of already-developed scenarios as training vehicles for time-poor individuals in focussed contexts $(34,35,36)$, we remained sensitive to Bowman et al.'s (17) critique of the use of such scenarios in exploring complex and ambiguous issues, and of the difficulties of engaging multiple stakeholders with diverse interests (cf. 37). Overall, whilst accepting that both IL and BLM scenario methods promote stakeholder involvement, we were aware of extant empirical evidence that scenario development may not impact subsequent decision making (11), especially in public policy settings $(5,10,26)$.

In light of the issues raised by the literature, and with the requirement that our scenario workshops be both short in duration but strong in implications for policymaking, we developed and implemented the scenario improvisation (SI) approach that we outline and discuss in the following sections.

\section{Scenario project method}

The scenario development process that we adopted involved both inductive and deductive thinking, both (i) building a set of forward-chaining normative scenarios through the 'intuitive logics' (9) of cause-effect thinking, and also (ii) employing elements of 'backwards logic' (32) in which a single 'desired' future scenario is interrogated in order to create and develop the effect-cause chain that would lead to it (38). Throughout, we remained mindful that the outcomes of the scenario workshops must provide clear input to public policy development (cf. 17). 


\subsection{Scenario method in the overall research program context}

The overall research project was undertaken through a multi-method program that included not only the scenario exercise discussed here, but also desk research on; economic and demographic data, industry analysis, and climate and ecology reports. In addition, a series of cases studies were undertaken of resource-based enterprises, along with labour market data analysis, and a series of key respondent interviews. Eighty-one interviews were conducted, of which 24 were with participants in the later scenario workshops. With the project covering a wide range of industry sectors, including; agriculture, forestry, coal extraction, and electricity generation; and with much volatility surrounding future possibilities, the inclusion of scenario workshops in the overall project proposal and research design was specifically intended to engage all stakeholders in a 'democratic conversation' in which conflict, ambiguity and uncertainty would be accepted and explicitly acknowledged. The intent was to prompt innovative and challenging reflection on potential futures informed by research of the present and recent past. The key objective was to elicit a common understanding of the different ways in which the future might unfold over the next decade, what would drive different outcomes, and what key issues require attention in the present or immediate future.

The Latrobe Valley region was agreed by all participants in the scenario workshops to be facing critical social, economic and environmental uncertainties and, as such, it was agreed that the future that will unfold would not be an extrapolation of the present or recent past. Nonetheless, there was a general view that the future must develop from the present, which is, of course, the result of a past sequence/interaction of both significant contextual events and actions of the powerful. However, this sequence was not viewed as having the determinism of path dependency; rather the focus was on plausible alternatives and possibilities.

\subsection{Designing the scenario process}

The scenario facilitator, with extensive experience of scenario practice and acknowledged theoretical expertise, was able to draw upon the various industry and interview reports produced by the research team and the project itself was scheduled to run over about six months. However, it was known that there would be only limited opportunities for direct engagement with the key stakeholders as a group, since all were senior members of their respective organizations with extensive commitments, limited availability and resultant difficulties in coordinating diaries for group engagement. This constraint underpinned our development of scenario improvisation.

Within the overall research structure of this project, and building on the research team's work and informant interviews, our approach to the scenario workshops was developed specifically to respond to the following issues:

1. How can we engage the 'broad' stakeholder constituency (39) with diverse values, beliefs and moral/ethical frameworks in an open and inclusive conversation? 
2. How do we focus discussion on possibilities for the future and avoid regressing to, or remaining fixed in established mindsets about the present, informed by the past?

3. How do we maintain the complexity, ambiguity and uncertainty surrounding the many factors that constitute the overarching research topic without reduction and exclusion?

4. How can we prompt the development and discussion of policy options - and their joint implementation by stakeholder groupings through their articulated action?

5. How can we facilitate a 'democratic conversation' that responds to these questions whilst acknowledging the unavoidable play of power, politics and competing rationalities $(28,40)$ ?

We considered that the type of open discussion sought would best be generated through use of scenario method based on intuitive logics (IL) (33), whereby the causeeffect chain of scenario building is grounded in knowledge and interpretation of the present - identifying current 'driving forces' (24). However, as outlined above, we were also highly cognisant that the key stakeholders that we wished to engage from a range of groups and organizations would be time-poor and unlikely to be able to commit to the timeframes implicated by, for example, the 'basic scenario method' of IL analysis (cf. 2).

\subsection{Overview of the scenario workshop program}

The process of stakeholder engagement took place over a series of three 90minute scenario workshops, albeit participant commitments then required the first workshop to be held in two sessions several days apart. Hereafter, we will refer to the various sessions as follows:

Scenario Workshop 1

Session 1 (2 key stakeholder participants + 3 research team members)

Session $2(8+4)$

Scenario Workshop $2 \quad$ Session $3(9+3)$

Scenario Workshop $3 \quad$ Session $4(13+5)$

Some of these sessions were attended by Commonwealth and Victorian State representatives. All sessions were recorded and transcribed and, as we shall discuss, close-reading of the transcripts provided the basis for the research team to refine, revise, reframe and re-present the scenarios in an iterative manner. Through these iterative cycles, the scenario narratives transformed from being products of the research team to being co-creations with regional stakeholders who took ownership of them.

In preparation for the first round of engagement (Session 1), the scenario facilitator worked with the research team to construct two outline 'extreme scenarios'. These were designed to probe plausible best- and worst-case futures in the year 2022 . The process of initial construction followed the general form of Wright and Cairns' (2) step-by-step technique for extreme scenario generation using the BLM method, but with no direct stakeholder involvement. However, the foci of the scenarios were drawn from content analysis of the various project reports compiled by the team over months of 
inquiry, as outlined above. From this array of primary and secondary data, the 'driving forces' of the present were drawn, key factors established and critical uncertainties of the future identified. It was around potential 'best' and 'worst' case outcomes of these uncertainties that the two scenario narratives were constructed. The overall sequence of scenario development, presentation, refinement and completion is shown in Figure 1, along with the key research team and stakeholder inputs to these.

\section{INSERT FIGURE 1 ABOUT HERE}

The initial scenario outlines were first delivered to two leading opinion makers from the region, one each from the agriculture and labour sectors. Session 1 commenced with caveats that the outlines were not predictions, were specifically designed to provoke and challenge, and with an open invitation that the two participants should confirm, reject, interrogate, refine or revise the storylines. These caveats were repeated at all sessions, along with a clear set of 'ground rules' for the conversation, drawn from the basic IL method. These included the proscription of any critical response to the contributions of others, and ruling that responses were limited to questions of clarification: Who might do this? Why do you think this might happen? When might this happen? How do you think this might be resolved? Only if every member of the group, including the originator, agreed that an idea was beyond plausibility would it be removed from the discussion - something that did not happen at any time.

Based upon discussion at session 1 , the two scenario outlines were refined and enhanced and so the presentation at the start of session 2, to a larger cohort of stakeholders, already incorporated other stakeholders' input to the narratives. This process of iterative co-design continued over sessions 3 and 4, as the two scenarios were discussed and debated. After each session, they were rewritten by the facilitator based on the transcripts, and then re-issued to participants in advance of the next session. The later sessions started with questioning of plausibility and possibility for these revised narratives before opening up debate on the issues raised by them. As a result, the two scenarios transferred from initial research team authorship, through interrogation and refinement of them by the stakeholders, to fall under the 'ownership' of the participants.

Prior to the third workshop (session 4), and based upon 'problem' issues raised by participants in the earlier sessions, a third scenario was developed, but was not circulated prior to the session. Here, the improvisation process led the research team to identify one specific issue that was introduced to the discussion by a participant as a 'weakness' of the region, namely, the lack of a single, focal regional city. Linking this to other 'problems' that surfaced in the workshops, the team reinterpreted the issue as a potential source of strength within this scenario. As will be discussed, the aim here was to stretch participants' thinking on problems by reframing these and re-presenting them as opportunities - offering both challenge and familiarity.

Following presentation of the third scenario, comment was invited on its plausibility - could actions be taken to promote its occurrence? Thereafter, the final 
session focussed on discussion with and amongst the stakeholders on actions that they might - individually, collectively, or with others - initiate in the immediate future in order to: a) influence the unfolding of the future towards the best case, b) steer away from the worst case, or c) where the actions of the self-interested stakeholders were, at best, weak in response to an unfolding future, consider strategies for resilience in the face of adverse outcomes.

By reference to elements of the discussion transcripts over the four sessions, we will next consider and discuss the emerging collective understanding of the participants, and the key individual contributions that formed foundational elements of this understanding.

\section{Scenario workshops - summary of content and issues}

In this part, we provide an account of the workshop content and issues raised. While our illustrative examples are selective we have sought to ensure that they are not exclusive. All workshops were introduced with the caveat that the presented scenarios were not predictions of any probable or likely future, but offered arguably plausible stories of unfolding futures - to spark debate and discussion about change and causality.

The lead facilitator introduced himself as an agent provocateur, to challenge and provoke stakeholders' thinking.

\subsection{Scenario workshop 1 - sessions 1 and 2}

The first extreme scenario presented, with the title Paradise Lost, opened with the words:

"Looking back now from 2022, what you see around you is derelict industrial buildings and sites, vacant shops with faded 'to lease' signs, ill-kept and abandoned houses and a general air of dereliction. This state comes at the end of a decade of continuing global economic turmoil, conflict...[] protectionist policies... [] and poor relations between Australia and its immediate neighbours. At the same time, in the Australian context, there was a failure to integrate policy and planning..." (4, pp. 202-203.).

In contrast, the second extreme scenario read out, $A$ Future for the Taking, began: "Looking back to 2012, there was a positive vision of the Latrobe Valley region of the future that was built on the foundations of the key resource industries. There was, however, acknowledgement of the need for adaptation and change, recognition of the core value of resources to the region, focussed education and training to meet social and industry needs, and advocacy for necessary infrastructure development, particularly rail..." (4, p. 201).

Initial reactions to both scenarios broadly supported both possibility and plausibility, with comments such as; "I think it's a good starting point...[] it mightn't be as black as you have outlined but the reality check is there", "There are some challenges. We've got to drill down each of the challenges" and, "My first reaction would be, both of 
them are designed to be extreme and lack practicality. However, both of them head in directions that I see as being relevant".

Picking up the challenge presented by Paradise Lost, one member commented, "We can take this headline, and we'll drag our bums around the place and say, woe is me, the world is bad, why bother trying; or, we can grab the thing by the scruff of the neck and say, we're going to make something of this". This future was certainly viewed as a wake-up call to events and outcomes that were, in part, seen as not only possible but highly likely, as in, "Yes, a worst-case scenario, but there are aspects of that which, I think, are going to occur. There are aspects of that which are our future".

Reviewing the transcripts of these two sessions at a later date, before scenario workshop 3, several points of interest were noted. First, there was no discussion by participants of the concept that would be raised in session 3 (Workshop 2) and that would later underpin the third, improvisational scenario. This was the concept of Latrobe City as a coherent and meaningful lived space. For participants in these sessions, Latrobe City was mentioned in passing as a bureaucratic functional entity. Only in Workshop 2 would we learn that this top-down government initiative had been designed as a community and culture integration concept, but had been allowed to lapse due to lack of funding and lack of engagement with the community to foster development.

Second, discussion of transport infrastructure was limited, generally critical in nature, but seemingly key to the region. One participant stated, "The transport infrastructure stinks, but we're working on that, you know?" However, another responded that, "The local community can't develop the appropriate rail or transport linkages", whilst a third asked, "When are we going to get a decision on what the future transport and logistics connections are, between here and our export destinations or (Melbourne)?" One member stated, "You've only got to look at our roads and rail and whatever...[] There just doesn't seem to be that long term vision beyond the next election or the next budget." For another participant, improvements to the rail network only allowed people to escape the high Melbourne house prices whilst continuing to work there. He expressed the view that, "You can understand that the people will come out here, an hour and a half from the city by rail, for a beautiful lifestyle. Of course you would, and you buy house and land packages for a small proportion of what you get in Melbourne."

Finally, the topic of local collaboration was raised, but the general view was that internal competition between centres and organizations dominated. Speaking of a proposal to develop a food industry cluster, one participant said, "So often, they've been brought into a room and tried to work something up, but they've seen each other as competitors, which they are. That's the only thing they've seen."

Notwithstanding these fairly negative comments, there was an air of optimism and desire to bring about positive change whilst recognising the problems to be faced. As one senior member put it:

"For me, it comes back to that transformational stuff. I think we've got to have a very clear picture about our future and say, 'That's where we're heading'...[] It would be nice, 
wouldn't it? But also, I grapple with how. You know, like, at the moment, we've sort of got some - you know, there's some sort of random thoughts on maybe strategic future and where we're heading, but it's the how - what are the enablers to get us there? I think we need some help in that."

In line with the illustrative comments offered here, the consensus of the participant group was that both scenarios were entirely plausible in broad terms, that some of the worst case outcomes were likely to happen whatever, but the challenge was there for the stakeholder community to grab the issues 'by the scruff of the neck'. On this basis, the team returned to base in Melbourne and refined the first two scenarios.

\subsection{Scenario workshop 2 - session 3}

No substantive change was made to the two scenarios, although descriptions of critical outcomes were expanded and contextual detail added to bring the narratives to life for the local audience. When introducing this session, and based upon the response to the stories at the first two workshops, the team stated that if these visions appeared by and large believable to the participants, then together we must look at the driving forces, events and decisions that would lead the region towards one or other of these end states, or somewhere in between. But first, we sought feedback on the scenarios that we had refined - and were told immediately by one member, "Both of them are possible and plausible". Picking up on this remark and opening up debate on what action was required, another member commented:

"Scenario (two) is obviously the preferred one...[] It's achievable, but I think all levels of government have got to get behind it to drive it. I don't think that has traditionally happened. You know, they haven't been willing to put resources in...[] I think in the past they have not been necessarily ready to listen to the regions. We often get the - we know better than you - kind of attitude".

This critical comment on governments at all levels was made in front of representatives of Federal, State and local government.

Commenting on local feelings of helplessness, one member suggested, "We've got a lot of despairism (sic)", whilst another highlighted fragmentation - "There are many other issues which the people in Gippsland collectively don't have an agreed view about. They don't all agree on climate change - and that's holding us back". These issues of helplessness and division were then reflected again onto the political landscape with the comment that, "In the political climate that we're in, there just seems to be one side making decisions and the other just going against it...[] Whatever political persuasion you are, I don't think there's any real leadership anywhere at the moment...[] It's all about retaining government".

These comments on divisive, oppositional political exchanges led into debate on the need for collaborative engagement to address the region's issues, although this was seen as not an easy option, with the following exchange:

"There's only ever been one particular project that...[] got all of those partners together and believe me, it was an absolute nightmare...[] There needs to be more of that collaboration". 
"Well the major problem was, was ownership I guess. Each particular party at the table wanted control. I guess that was an issue".

"I certainly think from that perspective of collaboration that would be a basis to start on; understanding what you're all there to do and what your authorising environments are and those sorts of things. But I do think collaboration's important".

"We're a large area and a diverse area as well. I think communication is obviously a key factor as well. If we don't communicate amongst ourselves better we can't expect people coming in with confidence to support what's happening".

At this stage the group recognised both the need for collaborative approaches and the difficulties that they, as key actors, faced in, "How do we bring that together?...[] It's really difficult". They also acknowledged the obstacles they faced in a community where, "One of the factors is low aspiration. Low aspiration basically means we're not creating an environment of hope".

Picking up on this, one participant recalled a top-down initiative to create some sense of community optimism through bringing the various towns along the Latrobe Valley together under the banner Latrobe City. Another member commented, "Latrobe City started, but, you know, it was again something funded by a government and when the funds stopped the initiative stopped...[] Many of us in the room were probably ambassadors of that program...[] But it's like people have said before, government funding - the biggest problem with it, is it's short term and you never know when it's going to start and stop". In response, another participant suggested, "I actually think the theme to that...[] is something that, as organisations, it's something we can very easily collaborate on".

Several further positive comments were made about the potential of the Latrobe City brand, including one participant's statement, "I'm not ashamed to live in Latrobe City. What's wrong with Latrobe City? It's an amazing brand, you know. I live in Moe, a suburb of Latrobe City. It's fantastic", to which another added, "Well why aren't we called Latrobe City...[] I think it's an exciting option as an opinion". However, the issue of whether or how the populace might be brought on board was seen as critical. As one stated, "I think that's a big challenge for us all to think about in this process. How do we bring them along, how do we get them engaged and owning this process. Because without them I don't think we will succeed".

We knew that Latrobe City had been mentioned in passing as a bureaucratic entity in Workshop 1 and the original intent that it should serve as a focus for 'community optimism' was now mentioned here. Despite the apparent enthusiasm for the concept of Latrobe City, the topic was not followed up during the session, and earlier failure was put down to lack of government funding. However, another subject was raised that the researchers were to see as linked and that was to prompt critical thinking on conceptualisations of the 'city'.

Later in this session, one participant commented, "One of the difficulties we've got is that we don't have a single regional centre like the rest of Victoria might have. So we don't have a Bendigo or a Ballarat or a Geelong. We've got a number of significant towns, but we don't have that single focus". Participants did not make any link between this absence and that of the proposed 'single focus' offered through Latrobe City. Identifying 
this lack of linkage in close reading of the transcripts, the researchers were prompted to question whether participants were able to link ideas of a conceptual 'place' - as in Latrobe City - and physical 'space' - as in the existing towns mentioned in other regions. Through discussion of this question, the idea of giving Latrobe City a 'concrete reality' in a third scenario was surfaced - a reality to be constructed on foundations that would bring both familiarity and challenge to participants. This would be achieved through reframing several problem issues put forward by participants to re-present them as potential opportunities. One of these was transport infrastructure.

At this session, the subject of transport was again raised and seen as being of critical importance. One member stated, "Transport's critical - absolutely - for domestic or businesses - just absolutely critical”. Whilst the infrastructure was acknowledged as being present, there was comment on inadequacy of capacity to enable ease of movement. One commentator stated, "The Sale community can't access Latrobe community and vice versa at the right times of the day so there's a lot of transport issues and that's just talking about the corridor. If we're looking at talking about off the corridor well, you know, there's a heap more". There was some discussion of need for improvement, but little on how this might be achieved.

As both external facilitators of the conversations and interpreters of signals that emerged from them, we were later to pick up on these threads of negative conversation and seek to reframe the underpinning ideas as opportunities. In this, we also sought to challenge a further negativity that participants now turned to, "that mindset that still bedevils the region quite frankly". "The mindset is - we're waiting for government to make the decision about our future". As workshop three drew to a close, it appeared that optimism for a brighter future was overlaid by feelings of negativity about the present "Eventually it may achieve the grand vision...[] I still think that eventually that sort of vision will be achieved, but it will be a long time coming". "The bit that's missing is...[] How do you engage in a conversation with your own community to actually - to validate that vision?"

As they left this session, participants reflected on how they had brought critical discussion of issues to the table, aired some pretty contentious views about each others' agencies and organisations, had finished with perhaps negative thoughts, yet had left, within our tape-recordings, ideas and information that we could extract and summarise in order to highlight key issues - both positive and negative and both coherently and divisively perceived by the group. The research team extracted and then summarised these issues in a report that was circulated to all participants, along with the third iteration of revisions to the two scenarios before the final workshop. The key issues identified were focussed specifically on the problems of collaboration between multiple agencies and interest groupings.

\subsection{Scenario workshop 3 - session 4}

Introducing the final scenario workshop, the lead facilitator read out a third scenario. This was developed with specific reference to the concept raised by 
participants in workshop three, the notion of Latrobe City. As outlined above, this was seen as an exercise that had faltered through lack of funding and commitment by a remote government. The conceptual possibilities for Latrobe City to offer a meaningful focus for integration of dispersed activities and interests, in line with existing regional cities elsewhere, had not been recognised.

Seeking to prompt new thinking on the possibilities through reframing the 'problem' of Latrobe City, the team presented a narrative that began:

"The map of the region in 2022 shows clearly how the key infrastructure corridor that existed and was being developed a decade ago has been exploited and expanded as the core of a revitalised region. What existed only as a name on a few road signs and buildings in 2012 has become the central focus of activity, identity and pride within Gippsland region - Latrobe City. This vibrant new City stretches along much of the Princes Highway...[] The Highway, the rail line - now double-track and electrified along its full length - and the fibre-optic broadband network link the parts of the City and its air transport and logistics hubs"

The narrative ended, "Welcome to Latrobe City, a centre of excellence for industry, culture, tourism, leisure and education, pride of our nation and internationally acclaimed." (4, pp. 207-208).

Asked by the facilitator, whether this scenario was plausible, the immediate response from one participant - an elder statesman of the region - was, "What you're saying is dare to dream?" Another team member responded, "Why not?" The conversation continued, "Exactly, because even if you do stumble at the higher level, you'll probably achieve something and clearly there isn't a unified feeling of pride or hope in many places". Echoed around the participant group, the words of their own became the title for the third scenario, Dare to Dream.

This initial response stimulated further intense discussion. First, one participant commented, "Well, Latrobe City brand has a very powerful energy in my opinion...[] there's so many Latrobe City things, yet we sort of seem to be scared to call the region Latrobe City". Another responded, "I think there is a lack of pride among many people which springs significantly from ignorance of what we have. I think that unity would help...[] There's too much, perhaps, self centred-ness and not seeing ourselves as a wider area, narrow thinking, rather than looking at the wider picture". This contribution appeared to acknowledge the regional myopia, of not seeing what conceptual attributes existed, rather than focussing on what physical attributes were lacking. However, another participant then commented, "The thing that struck me when you were speaking was it's quite a vision and would require significant amount of investment...[] It needs investment from somewhere else". This "would require both government and private finance, especially on the private finance side of things". Here, the responsibility for promoting action appeared to be passed to some other entity, 'elsewhere' than in the region itself.

Concerns were then voiced about how the broader community may or may not engage with the concept - "I think it needs the support of the whole community and we don't have that...[] Unless you got the base of the community supporting it and agreeing with it and all that, it doesn't go anywhere". "There's a whole lot of others down at the 
bottom who couldn't care less". Picking up on lack of community engagement, another participant commented, "There's some quite key vision statements in there but I think we're not well understood or appreciated by the general community, so how can we get towards them if we don't actually understand". Commenting on the participants' role in understanding and creating understanding, one member responded, "Maybe we're not adequate leaders".

Following this critical reflection on engagement and their own possible limitations as adequate leaders, the air of negativity was fairly quickly put aside. The topic of 'leadership' was not followed up as a matter for discussion, but appeared to be enacted. The group now began to debate the key issues put forward by the research team from the content analysis of the first three sessions, along with ideas on their individual and collective responsibilities to take a lead towards a best-case future. Several members made specific commitments on follow up actions:

"So I believe out of all this, we need to have a vision and a plan, to work to...[] Obviously the biggest challenge is to be able to work together and talk about those structures about trusting three or four or five organisations that represent the right areas...[] We understand when those five people walk into the room, that the majority of the people are represented and are going to be heard".

"I think that makes sense".

"The people become the plan makers instead of the plan takers and the government actually are the implementers and get help with investment and funding".

As this session rounded up, we were able to summarise the key issues that the group had agreed to take a leadership role on, and also their commitment to individual and collective follow up action:

"You know that if you don't deal with these issues, then you're convinced in your own minds that you're going to end up in 2022 with derelict industrial sites, boarded up houses and a region that's in a pretty bad state. So over to you to work with your colleagues, your neighbours, your friends - people who disagree with you at the moment and...[]".

The key issues identified from content analysis of the transcripts of the two workshops (sessions 1-3) - and then discussed at workshop three in relation to all three scenarios - were subsequently refined and reported by the team (4, pp. 204-206). In summary, these issues were grouped under the following broad headings: a) infrastructure policy and planning, largely around failure to address integration; b) land use policy and planning, again around failure to integrate and fragmentation of decision making; c) power generation policy, and lack of political will to address the environmental impact of brown coal generation; d) forestry policy, planning and society engagement, with further failure to plan strategically but also lack of 'social licence' for the industry; e) education, training and labour supply, here with recognition of regional strengths in some areas but not matched to emerging demands for new skills; f) cultural issues, where the issue of fragmentation was paramount and a culture of social dependency was identified as deep rooted; g) economic conditions, where external investment was considered to be not aligned with local priorities and investment needs, and finally; h) lack of decision making on key issues, where short electoral cycles, 
conflicts across levels government, and vested interests and power inequalities were seen to militate against best case outcomes.

Each of these issues signify failures of policy and process from, in many cases, the participants' own organisations. Nonetheless, they were considered serious in terms of both regional need and of policy and planning implications. In their discussion during workshop three, the participants identified and agreed to pursue the following questions beyond the workshop series' end:

1. What decision and what policy is required in response to the issue?

2. Why is this response required in order to ensure planning and action?

3. What are the contexts - local, State, Federal; public, private - in which power lies to ensure this response?

4. Who must take responsibility for ensuring that policy is enacted?

5. What is the required timescale within which action must be taken?

6. What are the economic and financial implications of action?

Finally, it was seen as crucial that each issue be addressed in terms of:

7. What are the social, economic and ecological implications of any failure to initiate a response to this issue?

\section{Discussion}

Our research shows that conventional scenario development offers but one element of the practical 'toolbox' required in order to progress through stages of complex problem identification, analysis, reframing and generation of options for its resolution (cf. 11). The full project had a substantial budget and extensive research expertise but, in undertaking the scenario analysis, we had limited access to the time of the key stakeholders (cf. 12). For deep engagement with the key issue, an extensive time commitment is normally expected from participants. For example, an IL workshop of 24 hours duration is expected to be, in essence, exploratory rather than informing planning and policy [cf. 23, 25]. We made the decision that the first iteration of scenario narratives must be written by the research team, thereby requiring that both process and content expertise be brought together within the team. However, we also sought to ensure that the stakeholders would develop a sense of ownership of the scenarios (cf. the failure in this respect documented in 17).

The SI scenario process did not directly offer within-workshop solutions to the issues generated in session 4 , and so aligns with the notion that scenario development itself does not necessarily lead to decision making - action that is implicit in the term 'scenario planning' (cf. 11). However, the outcomes of the full research project are indicative that the scenarios contributed to an evidence-based assessment of economic opportunity for the Latrobe Valley region. The Final Report (4) included both the full scenario narratives and, also, an overview of the process whereby a democratic conversation had been facilitated, rather than allowing vested interests and power structures to determine the outcomes. The report provided fact, information and 
perception to inform debates and understandings about regional structural adjustment, focusing on the political, economic and social consequences of industry transition.

The reception of the report, its subsequent publication in the public domain (2012) and its adoption by Federal Government as a vehicle for informing public policy indicate that it met the requirements of utility for government and other key stakeholders. The scenario workshops facilitated a focussed discussion, whereby the core industrial and service centre was seen as central to the region's future but where debate occurred with reference to a set of extant political arrangements in which there was no established and accountable form of regional governance, beyond the six council boundaries. The Gippsland Local Government Network, an 'alliance' of the six councils, held no executive capacity in relation to the region as a whole. However, a range of interest groups focussed on Gippsland as a whole (e.g., Committee for Gippsland, Agribusiness Gippsland Inc., and the Gippsland Trades and Labour Council). Participant discussion took place with a clear awareness of these arrangements, since there was reference to each of these organisations across the workshops and over a range of concerns.

The focus on the Latrobe City scenario became a way of guiding public opinion and promoting policy decisions for the social and economic development of the region. It indicated an aspiration for an urban hub and a regional focus. The largest concentration of the Gippsland population reside and work within the City boundaries, a place where the political concern with transition derives from a past marked by privatisation of state energy assets and the accompanying features of deindustrialisation. It is against this background that in April 2012 the Gippsland Trades and Labour Council together with Latrobe City Council, the State Government Victoria and RMIT University promoted a "Gippsland Industries in Transition Future Business, Investment and Employment Opportunities" conference, attended by 41 organisations. Reference to 'Latrobe City' as reflected in the workshops and articulated in the third scenario indicates an aspiration for a place of regional governance - rather than mere physical space - a place which may become part of long term political debate in the broader region.

The scenario workshops also contributed to policy formulation and enrichment in a variety of indirect ways. First, these workshops underwrote particular sets of outlooks that were continually in the process of development. Second, the workshop discussion reflected unfolding views about regional politics. The Committee of Gippsland, represented at Workshop 3, later expressed views consistent with the content and focus of the workshop discussion, stating publicly the need that, "Working together: Government, business, unions and other regional stakeholders work cooperatively to diversity and grow the region's economy" (41). The scenario workshops enabled the crystallization of a narrative about the future whereby, in diverse and uneven ways, participants were enabled to continue to contribute to an overarching vision of how the region could change and develop.

In line with Clark et al.'s (42) triad of knowledge criteria, we posit that the Final Report offered: i) credibility, in that its content was seen by these stakeholders as being rigorous and accurate; ii) salience, in being highly relevant to the needs of policy makers, 
and; iii) legitimacy, whereby diverse and conflicting views were incorporated and assessed fairly. If the project outputs are to be adopted by key decision makers as meaningful inputs to their deliberations on policy and planning, these three attributes must be immediately identifiable. In our exercise, we sought to assure credibility through iterative, inductive co-creation of the final scenario narratives with key stakeholders. Through the collaborative inquiry of the scenario workshops, participants brought salience to the final narratives. Finally, through adoption of our 'ground rules' of democratic conversation, legitimacy was ensured.

Assessing the SI scenario development process in relation to recent critical analysis of the effectiveness of scenario methods (5), this project overcame major obstacles perceived by others. For example, Rickards et al.'s study of multi-stakeholder climate adaptation scenario projects elicited data on perceived problems that prevent scenarios from informing strategy. These included: lack of linkage between scenario project outcomes and decision making (72\%); inadequate resources for the project (66\%); difficulty in integrating knowledge from diverse fields (65\%); lack of information about how best to use scenarios (64\%), and; insufficient data and evidence to inform the scenarios $(60 \%)$. In relation to this project, we would posit that each of these obstacles has been overtly addressed and overcome - through advance planning and preparation for the larger research project, and also by the adoption of our scenario improvisation approach - drawing on the strengths of extant forms whilst addressing issues of critique.

We term our new approach one of 'scenario improvisation' (SI), in that we adopted elements of both intuitive logics (IL) and backwards logic (BLM) approaches, yet were not bound by the specific multi-stage scenario process of either. In addition, the iterative co-design of the first two scenario narratives involved processes of both inductive and deductive reasoning, and these were undertaken both by the research team and the involved stakeholders. Also, we brought Flyvbjerg's $(28,40)$ value-rational phronetic inquiry framework into the discussion, thus invoking the key component of critical scenario method (CSM), in order to focus discussion towards a concept of the 'common good', rather than self-interest of specific stakeholder groupings.

Drawing upon the sources we have cited in relation to these various scenario methods - IL, BLM, CSM, SI - we summarize what we see as the key differences and similarities within Table 1, where the focus is on scenario exercises that are intended to prompt and inform planning and policy decisions.

\section{INSERT TABLE 1 ABOUT HERE}

As documented, the SI scenario approach contains elements that address the acknowledged limitations of scenario methods as tools for informing policy and planning $(5,10)$. However, the SI approach that we have described involves a much broader range of resources than many scenario interventions, including: key stakeholders with both decision making responsibility for the issue at hand and contextual knowledge and expertise to inform inquiry; a research team that brings 
multidisciplinary expertise and diverse research skills; a skilled facilitator with both theoretical and practical knowledge of scenario methods; expertise in writing scenario narratives that will stretch the boundaries of plausibility, and; the necessary resources to support a broad research agenda within which scenario analysis is a key component.

One key role of the scenario facilitator and research team in the SI approach lies in identifying critical negative issues raised by participants that offer the potential for reframing as opportunities and challenge to bounded rationalities. This is illustrated in the origins and outlines of the third, Dare to Dream, scenario. In the first three sessions, participants' discussion focused on the quotidian of fragmentation, competition and conflict between the various regional towns. There are several such towns of roughly equal size in the Latrobe Valley region, lying to the south east of the state capital Melbourne, with residents of each generally seeing their own town as the 'key' centre. As participants catalogued an array of inter-community conflicts, at the same time they lamented the lack of an identifiable key city (see Figure 2), as exists in other regions to the north, west and south west of Melbourne. It was the scenario team members who picked up on these various strands of conversation, linked them to discussion of local road, rail and broadband corridors - also, to national and international discussions of urban congestion - and reframed the 'problems' as opportunities (Figure 2). From this, arose the concept of Latrobe City as a new form of regional centre - or group of centres dispersed as 'ribs' along the transport and communication 'backbone'.

\section{INSERT FIGURE 2 ABOUT HERE.}

Whilst the steps of the scenario improvisation process that we outline here may be codified for use by others, whether in the practice arena or in teaching, there is a key element of creativity that must be appreciated and understood. As experienced reflective scenario practitioners, we are accustomed to seeking out the 'critical uncertainties' facing participants and facilitating their exploration of potential and possible future out-turns. However, here we outline a process of identification of various 'problems' facing the region, reframing these as potential opportunities, and representing them in an improvised scenario. In doing this, we ensured that the presentation offered both challenge and familiarity to participants. The challenge lay in the reframing of the problems, whilst the familiarity lay in giving 'concrete reality' to the presentation. The 'reality' of Latrobe City lay in it having local foundations of transport infrastructure and other existing facilities, and being set alongside other existing regional cities around Melbourne as a physical 'space' to be compared with them, not as an absent 'place' within the region. We view this creative, critical reflective practice element as crucial to SI, but see it as a skill that cannot be taught by rote.

Whilst Latrobe City may remain only a dream - but, notably, a dream with physical form and shared by all stakeholder groupings within the workshops - the concept served a key role in galvanizing thinking on coordinated action within session 4, bringing a focus on shared agenda items rather than on individual aspirations, whether community or organization-based. Identifying the 'common good' is thus a fundamental 
focus of the SI approach. Once identified and made salient by an observant research team, it can promote articulated action between diverse stakeholder groupings. Our analysis thus reveals the source of the positive outcomes of the IL-method-based Mont Fleur scenarios [25] - which were created at the time of the transition to black majority rule in South Africa. In that exercise, similar, diverse, stakeholder groupings saw the need to avoid the occurrence of the negative 'Icarus' scenario - since all would lose in that eventuality. By contrast, our case study is an illustration of the power of scenario improvisation to provoke an analogous, co-ordinated, action of stakeholders - but with the constraint of limited time commitment by key stakeholder participants.

\section{Concluding remarks}

In this paper, we have outlined a novel application of scenario methods, that we term 'scenario improvisation' (SI). We did not follow a single, extant structured scenario method, but neither was our approach devoid of structure. Our focus was on applying scenario methods in the most appropriate way to engage time-poor key decision makers in a democratic conversation that would inform policy and planning on their region's future. Whilst the research team developed and delivered the initial scenario narratives, we focused attention on ensuring that our limited engagement with these decision makers enabled them to take ownership of the scenarios, establishing their credibility, salience and legitimacy [42]. Via a case-study approach that addressed current trends and future prospects, the outcomes of the scenario program informed a Final Report (4) that provided an evidence base for consideration of new models of economic sustainability, including flexible networked enterprises that are characteristic of economies with major employers in decline. The report offered a distinctive perspective on opportunities and constraints unfolding in the Latrobe Valley region in Australia over the next decade and has already informed planning and decision-making in the region, particularly with regard to regional workforce development and assistance.

Key elements of the scenario improvisation process were; engaging key stakeholders whilst limiting their time commitment, building upon their knowledge of the present and extant mental models whilst challenging their interpretations, reframing familiar ideas to create novel and challenging futures, and building both normative scenarios grounded in the present and extreme scenarios of envisaged futures. Together, these elements enabled the research team to construct a single scenario that exemplified the common good and thus promoted the expression of articulated action for its achievement amongst a diverse grouping of stakeholders.

More broadly, we consider that we contribute to discussion on how scenario methods might inform evidence-based policy development (cf. 5, 10) and might be more clearly related to future-oriented goals in relation to low-carbon economic conditions and sustainable futures (cf. 5, 9).

\section{Acknowledgements}


This research formed part of a larger project by members of the Centre for Sustainable Organisations and Work, RMIT University and we acknowledge the support and contribution of all members of the team (4). We also acknowledge the funding of the Federal Government that supported the project.

\section{References}

[1] P.J.H. Schoemaker, Scenario planning: a tool for strategic thinking. Sloan Manage. Rev. 36 (2) (1995) 25-40.

[2] G. Wright, G. Cairns, Scenario Thinking: Practical Approaches to the Future, Palgrave Macmillan, Houndmills, Hampshire, UK, 2011.

[3] W.R. Huss, E.J. Honton, Scenario planning - what style should you use? Long Range Planning (1987) 204 21-29.

[4] P. Fairbrother, D. Snell, G. Cairns, L. Bamberry, M. Tyler, M. Pape, C. Rioux, S.

Carroll-Bell, S. Suraci, Identification of Opportunities to Support Structural Adjustment in the Latrobe Valley: Final Report for Commonwealth Department of Regional Australia, Regional Development and Local Government, Centre for Sustainable Organisations and Work, Melbourne, 2012, available at http://mams.rmit.edu.au/2i29uab8gw0e.pdf.

[5] L. Rickards, J. Wiseman, T. Edwards, C. Biggs, The problem of fit: scenario planning and climate change adaptation in the public sector, Environment and Planning C: Government and Policy (2014) 32 641-662.

[6] A. Grübler, B. O'Neill, K. Riahi, V. Chirkov, A. Goujon, P. Kolp, I. Irommer, S. Scherbov, E. Slentoe, Regional, national, and spatially explicit scenarios of demographic and economic change based on SRES, Technol. Forecast. Soc. Change (2007) 74980 1029.

[7] J.A. Wardekker, A. de Jong, J.M Knoop, J.P. van der Sluijs, Operationalising a resilience approach to adapting an urban delta to uncertain climate changes, Technol. Forecast. Soc. Change (2010) 77 987-998.

[8] H.A. Von der Gracht, C. Stillings, C. An innovation-focused scenario process - a case from the materials producing industry, Technol. Forecast. Soc. Change (2013) 80 599610.

[9] N. Hughes, Towards improving the relevance of scenarios for public policy questions: a proposed methodological framework for policy relevant low carbon scenarios, Technol. Forecast. Soc. Change (2013) 80 687-698.

[10] A. Volkery, T. Ribeiro, Scenario planning in public policy: understanding use, impacts and the role of institutional context factors, Technol. Forecast. Soc. Change (2009) 76 1198-1207.

[11] G. Wright, G. Cairns, R. Bradfield, Scenario methodology: new developments in theory and practice: introduction to the special issue. Technol. Forecast. Soc. Change (2013) 80 561-565.

[12] B. Pincombe, S. Blunden, A. Pincombe, P. Dexter, Ascertaining a hierarchy of dimensions from time-poor experts: linking tactical vignettes to strategic scenarios. Technol. Forecast. Soc. Change (2013) 80 584-598. 
[13] F.A. O'Brien Scenario planning - lessons for practice from teaching and learning, European Journal of Operational Research (2004) 152 709-722.

[14] L.A. Franco, M. Meadows, S.J. Armstrong, Exploring individual differences in scenario planning workshops: a cognitive style framework, Technol. Forecast. Soc. Change (2013) 80 723-734.

[15] M. Godet, The art of scenarios and strategic planning: tools and pitfalls, Technol. Forecast. Soc. Change (2000) 65 3-22.

[16] G.P. Hodgkinson, I. Clarke, Exploring the cognitive significance of organizational strategizing: a dual-process framework and research agenda, Human Relations (2007) 60 243-255.

[17] G. Bowman, R.B. Mackay, S. Masrani, P. McKiernan, Storytelling and the scenario process: understanding failure and success. Technol. Forecast. Soc. Change (2013) 80 735-748.

[18] J. Quist, P. Vergragt, Past and future of backcasting: the shift to stakeholder participation and a proposal for a methodological framework, Futures (2006) 38 10271045.

[19] R.R. McWhorter, S.A. Lynham, An initial conceptualization of virtual scenario planning, Advances in Developing Human Resources (2014) 16 335-355.

[20] M.B.A. van Asselt, S.A. van't Klooster, S.A. Veenman, Coping with policy in foresight, Journal of Futures Studies, (2014) 19 (1) 53-76.

[21] R. Bradfield, G.Wright, G. Burt, G. Cairns, K. Van der Heijden, The origins and evolution of scenario techniques for long range business planning, Futures (2005) 37 795-812.

[22] G. Burt, G. Wright, R. Bradfield, G. Cairns, K. van der Heijden, The role of scenario planning in exploring the environment in view of the limitations of PEST and its derivatives, Int. Studies of Mgt. \& Org. (2006) 363 50-76.

[23] A. Tversky, D. Kahneman, The framing of decisions and the psychology of choice, Science (1981) 211 453-458.

[24] K. Van der Heijden, R. Bradfield, G. Burt, G. Cairns, G. Wright, The Sixth Sense: Accelerating Organizational Learning With Scenarios, Wiley, Chichester, UK, 2002.

[25] A. Kahane, The Mont Fleur Scenario, GBN, Emeryville, CA, 1991.

[26] G. Cairns, I. Ahmed, J. Mullett, G. Wright, Scenario method and stakeholder engagement: critical reflections on a climate change scenarios case study, Technol. Forecast. Soc. Change (2013) 80 1-10.

[27] G. Cairns, M. Śliwa, G. Wright, Problematizing international business futures through a 'critical scenario method', Futures (2010) 42 971-979.

[28] B. Flyvbjerg, Making Social Science Matter: Why Social Inquiry Fails and How it Can Succeed Again, Cambridge University Press, Cambridge, UK, 2001.

[29] M.P. Healey, G.P. Hodgkinson, Troubling future: scenarios and scenario planning for organizational decision making. in: G.P. Hodkinson and W. Starbuck (eds.) Organizational Decision Making. Oxford, Oxford University Press, 2008.

[30] K. Van der Heijden, Scenarios: The Art of Strategic Conversation (2 ${ }^{\text {nd }}$ ed.), Wiley, Chichester, UK, 2005. 
[31] K.H. Dreburg, Essence of backcasting, Futures (1996) 28 813-28.

[32] G. Wright, P. Goodwin, Decision making under low levels of predictability: enhancing the scenario method, International Journal of Forecasting (2009) 25 813-825. [33] H. Jungermann, M. Thuring, The use of mental models for generating scenarios, in: G. Wright and P. Ayton (eds.) Judgmental Forecasting, Wiley, London, 1987. [34] R.W. Jones, Problem-based learning: description, advantages, disadvantages, scenarios and facilitation, Anaesthesia and Intensive Care (2006) 34 485-488.

[35] H. Camerson, J. Limberger, Online learning: cross-cultural development in time poor environments, Journal of European Industrial Training (2004) 28 429-439.

[36] J. Kiely, N. Beamish, C. Armistead, Scenarios for future service encounters, The Service Industries Journal (2004) 24 131-149.

[37] M. Van Vliet, K. Kok, T. Veldkamp, Linking stakeholders and modellers in scenario studies: the use of fuzzy cognitive maps as a communication and learning tool, Futures (2010) 42 1-14.

[38] B. De Jouvenal, The Art of Conjecture, London, Weidenfeld \& Nicolson, 1967.

[39] R.E. Freeman, The politics of stakeholder theory: some future directions, Business Ethics Quarterly (1994) (4) 4 409-421.

[40] B. Flyvbjerg, Making organization research matter: power values and phronesis, in: B. Czarniawska and G. Sevón (Eds.) The Northern Lights: Organization Theory in Scandinavia, Liber Abstrakt - Copenhagen Business School Press, Copenhagen, 2003. [41] H. Rijs, M. Aldred, Submission to the directions for Latrobe Valley transition discussion paper, The Committee for Gippsland Inc., 12 May 2012, available at http://www.committeeforgippsland.com.au/docs/120512\%20Latrobe\%20Valley\%20T ransition\%20Discussion\%20Paper\%20C4G\%20Submission.pdf. [42] W. Clark, R. Mitchell, D. Cash, F. Alcock, Information as influence: how institutions mediate the impact of scientific assessments on global environmental affairs, Faculty Research Working Paper - RWP02-044, John F. Kennedy School of Government, Harvard, 2002. 


\begin{tabular}{|c|c|c|c|c|}
\hline \multicolumn{2}{|c|}{ Stage/activity } & \multirow{2}{*}{$\begin{array}{l}\text { Key inputs/actions } \\
\text { Desk research on context } \\
\text { Key informant interviews } \\
\text { Content analysis of } \\
\text { documents and transcripts } \\
\text { Background reports }\end{array}$} & \multirow[b]{2}{*}{$\begin{array}{l}\text { Key informants/actors } \\
\text { Economic, industry, } \\
\text { demographic etc. reports on the } \\
\text { region } \\
\text { Senior stakeholders in region } \\
\text { provide interviews } \\
\text { Research team undertake } \\
\text { content analysis and report } \\
\text { compilation }\end{array}$} & \multirow[b]{2}{*}{$\begin{array}{l}\text { Key issues } \\
\text { Comprehensive research } \\
\text { must be undertaken on } \\
\text { the context in which the } \\
\text { research question is } \\
\text { situated, gathering data, } \\
\text { perceptions and } \\
\text { perspectives broadly }\end{array}$} \\
\hline $\mathrm{A}$ & $\begin{array}{l}\text { Background } \\
\text { research }\end{array}$ & & & \\
\hline $\mathrm{B}$ & $\begin{array}{l}\text { Initial scenario } \\
\text { development }\end{array}$ & $\begin{array}{l}\text { Reports from Stage A inform } \\
\text { scenario analysis following } \\
\text { the 'basic method' of } \\
\text { inductive scenario building }\end{array}$ & $\begin{array}{l}\text { Experienced scenario facilitator } \\
\text { develops scenario outlines and } \\
\text { research team members } \\
\text { undertake sense-testing }\end{array}$ & $\begin{array}{l}\text { Facilitator must be able to } \\
\text { interpret research } \\
\text { reports to identify } \\
\text { 'driving forces', key } \\
\text { factors and initial critical } \\
\text { uncertainties }\end{array}$ \\
\hline $\mathrm{C}$ & $\begin{array}{l}\text { Scenario } \\
\text { Workshop } 1\end{array}$ & $\begin{array}{l}\text { Scenarios read to regional } \\
\text { stakeholders, opening debate } \\
\text { on possibility and plausibility } \\
\text { and on issues raised }\end{array}$ & $\begin{array}{l}\text { Stakeholder participants } \\
\text { interrogate scenario narratives } \\
\text { and lead on interpretation, with } \\
\text { facilitation from experienced } \\
\text { research team members }\end{array}$ & $\begin{array}{l}\text { Scenarios must be } \\
\text { accepted as possible and } \\
\text { plausible by stakeholders, } \\
\text { but must also challenge } \\
\text { their individual and } \\
\text { collective views }\end{array}$ \\
\hline $\mathrm{D}$ & $\begin{array}{l}\text { Scenario } \\
\text { refinement }\end{array}$ & $\begin{array}{l}\text { Transcripts from Stage C are } \\
\text { subjected to content analysis } \\
\text { and scenario narratives are } \\
\text { refined and reissued to } \\
\text { stakeholders }\end{array}$ & $\begin{array}{l}\text { Stakeholder participants } \\
\text { provide data, information and } \\
\text { perception through transcripts } \\
\text { Research team undertake } \\
\text { content analysis } \\
\text { Facilitator refines scenarios }\end{array}$ & $\begin{array}{l}\text { Revised and refined } \\
\text { scenarios must be } \\
\text { identified by stakeholders } \\
\text { as refinements of the first } \\
\text { iteration, based upon } \\
\text { their input, but } \\
\text { challenging their ideas }\end{array}$ \\
\hline$E$ & $\begin{array}{l}\text { Scenario } \\
\text { Workshop } 2\end{array}$ & $\begin{array}{l}\text { Scenarios read to regional } \\
\text { stakeholders, opening debate } \\
\text { on possibility and plausibility } \\
\text { and on issues raised, and on } \\
\text { key issues that will impact } \\
\text { the region's future }\end{array}$ & $\begin{array}{l}\text { Stakeholder participants } \\
\text { interrogate scenario narratives } \\
\text { and lead on interpretation, with } \\
\text { facilitation from experienced } \\
\text { research team members } \\
\text { Facilitator focuses on questions } \\
\text { of 'Why?', 'Who?', 'How?', } \\
\text { When?' etc. }\end{array}$ & $\begin{array}{l}\text { Scenarios must be } \\
\text { accepted as possible, } \\
\text { plausible and informed } \\
\text { by their Stage C input, but } \\
\text { must challenge their } \\
\text { views and stimulate } \\
\text { debate on the critical } \\
\text { uncertainties of the } \\
\text { future }\end{array}$ \\
\hline $\mathrm{F}$ & $\begin{array}{l}\text { Scenario } \\
\text { refinement and } \\
\text { improvisation }\end{array}$ & $\begin{array}{l}\text { Initial scenarios are further } \\
\text { refined based on Stage E } \\
\text { transcripts and issued to } \\
\text { stakeholders } \\
\text { Further 'improvised' scenario } \\
\text { narrative(s) developed to } \\
\text { provoke broader challenge }\end{array}$ & $\begin{array}{l}\text { Research team identify } \\
\text { 'problem' issues raised by } \\
\text { stakeholders without resolution } \\
\text { and seek to reframe these as } \\
\text { opportunities }\end{array}$ & $\begin{array}{l}\text { The improvised } \\
\text { scenario(s) must be } \\
\text { designed to make the } \\
\text { familiar unfamiliar, to } \\
\text { provoke challenge, but } \\
\text { aim to be credible and } \\
\text { relevant }\end{array}$ \\
\hline $\mathrm{G}$ & $\begin{array}{l}\text { Scenario } \\
\text { Workshop } 3\end{array}$ & $\begin{array}{l}\text { Revised initial scenarios are } \\
\text { agreed or finely tuned and } \\
\text { accepted } \\
\text { The new scenario content is } \\
\text { presented to stakeholders } \\
\text { and interrogated for } \\
\text { possibility and plausibility } \\
\text { Discussion is then focused on } \\
\text { key issues requiring action } \\
\text { and policy/planning } \\
\text { responses } \\
\text { Stakeholders agree } \\
\text { individual/collective action } \\
\text { agenda }\end{array}$ & $\begin{array}{l}\text { Research team present and } \\
\text { justify additional scenario } \\
\text { narratives - drawing on } \\
\text { research, expertise and } \\
\text { experience from other contexts } \\
\text { Stakeholders must justify any } \\
\text { rejection of ideas presented } \\
\text { Debate is then focused on the } \\
\text { key uncertainties, opportunities, } \\
\text { threats, etc. for the region and } \\
\text { on the actions required in the } \\
\text { present or near future in order } \\
\text { to seek the best possible future } \\
\text { outcomes }\end{array}$ & $\begin{array}{l}\text { Stakeholders must } \\
\text { recognise both the } \\
\text { 'problem' issues that } \\
\text { underpinned the new } \\
\text { scenario narratives, and } \\
\text { must understand and } \\
\text { agree the logic of the } \\
\text { possibilities and } \\
\text { opportunities derived } \\
\text { from them } \\
\text { Research team must have } \\
\text { the expertise and } \\
\text { credibility to justify and } \\
\text { support their arguments }\end{array}$ \\
\hline
\end{tabular}

Figure 1 - Illustrative mapping of scenario development to include 'scenario improvisation'. 


\begin{tabular}{|c|c|c|c|c|}
\hline $\begin{array}{l}\text { Scenario approach } \\
\text { Characteristics }\end{array}$ & IL & BLM & CSM & SI \\
\hline $\begin{array}{l}\text { Participant time } \\
\text { commitment }\end{array}$ & High & High & High & Low \\
\hline $\begin{array}{l}\text { Participant knowledge of } \\
\text { scenario construction } \\
\text { process (gained over the } \\
\text { exercise) }\end{array}$ & High & High & High & Low \\
\hline $\begin{array}{l}\text { Required knowledge of the } \\
\text { substantive issue of concern } \\
\text { by the workshop facilitators }\end{array}$ & Low/Medium & Low/Medium & Low/Medium & High \\
\hline $\begin{array}{l}\text { Role of participants in } \\
\text { scenario development }\end{array}$ & $\begin{array}{l}\text { Scenario } \\
\text { generators }\end{array}$ & $\begin{array}{l}\text { Scenario } \\
\text { generators }\end{array}$ & $\begin{array}{l}\text { Scenario } \\
\text { generators }\end{array}$ & $\begin{array}{l}\text { Respond and } \\
\text { refine }\end{array}$ \\
\hline Role of scenario facilitators & Facilitators & Facilitators & Facilitators & $\begin{array}{c}\text { Scenario } \\
\text { generators/ } \\
\text { Facilitators }\end{array}$ \\
\hline $\begin{array}{l}\text { Use of 'Remarkable person' } \\
\text { to generate challenge to } \\
\text { participants }\end{array}$ & Recommended & N/A & $\begin{array}{l}\text { Not listed - } \\
\text { optional }\end{array}$ & $\begin{array}{l}\text { Scenario team } \\
\text { function to } \\
\text { present } \\
\text { challenge }\end{array}$ \\
\hline Role of 'client' in scenarios & $\begin{array}{l}\text { External } \\
\text { observer }\end{array}$ & $\begin{array}{c}\text { Active } \\
\text { participant }\end{array}$ & $\begin{array}{c}\text { Not listed - } \\
\text { optional }\end{array}$ & $\begin{array}{l}\text { Reactive and } \\
\text { active }\end{array}$ \\
\hline Scenario iterations & Multiple & Multiple & Multiple & Multiple \\
\hline No. of scenarios & 4 & One or more & 4 & As appropriate \\
\hline $\begin{array}{l}\text { Form of scenario } \\
\text { development }\end{array}$ & $\begin{array}{l}\text { Multi-stage } \\
\text { structured }\end{array}$ & $\begin{array}{l}\text { Multi-stage } \\
\text { structured }\end{array}$ & $\begin{array}{l}\text { Multi-stage } \\
\text { structured }\end{array}$ & $\begin{array}{l}\text { Follow forms as } \\
\text { appropriate }\end{array}$ \\
\hline Mode of inquiry & Inductive & Deductive & Inductive & $\begin{array}{l}\text { Inductive/ } \\
\text { Deductive }\end{array}$ \\
\hline $\begin{array}{l}\text { Pre-workshop interviews by } \\
\text { scenario team }\end{array}$ & $\begin{array}{l}\text { Recommended } \\
\text { - not essential }\end{array}$ & Not essential & $\begin{array}{c}\text { Not listed - } \\
\text { optional }\end{array}$ & Essential \\
\hline $\begin{array}{l}\text { Background research on } \\
\text { issue }\end{array}$ & Participants & Participants & Participants & $\begin{array}{l}\text { Research/ } \\
\text { Scenario team }\end{array}$ \\
\hline
\end{tabular}

Table 1 - Summary of key characteristics of scenario approaches. 


\begin{tabular}{|c|c|c|}
\hline $\begin{array}{l}\text { Key actor input } \\
\text { Issue }\end{array}$ & $\begin{array}{l}\text { Participant/Stakeholder } \\
\text { 'problems' }\end{array}$ & $\begin{array}{l}\text { Scenario/Research Team } \\
\text { 'opportunities' and vision }\end{array}$ \\
\hline $\begin{array}{l}\text { 1. Fragmentation and } \\
\text { competition between towns }\end{array}$ & $\begin{array}{l}\text { "The law courts are in Morwell - } \\
\text { should have been in bloody } \\
\text { Traralgon!" } \\
\text { "It is just - you know, we've met } \\
\text { with people in the past that have } \\
\text { sort of said that - so you don't } \\
\text { want people from Moe or } \\
\text { Warragul or Traralgon." (Session } \\
\text { 3) }\end{array}$ & $\begin{array}{l}\text { Whilst the towns are of roughly } \\
\text { equal size and duplicate many } \\
\text { facilities, such as libraries, the } \\
\text { team focussed on developing } \\
\text { already shared facilities - e.g. } \\
\text { airport (Morwell) and university } \\
\text { campus (Churchill). }\end{array}$ \\
\hline 2. Lack of a larger regional city & $\begin{array}{l}\text { "One of the difficulties we've One } \\
\text { of the difficulties we've got is that } \\
\text { we don't have a single regional } \\
\text { centre like the rest of Victoria } \\
\text { might have. So we don't have a } \\
\text { Bendigo or a Ballarat or a } \\
\text { Geelong. We've got a number of } \\
\text { significant towns, but we don't } \\
\text { have that single focus." } \\
\text { (Session3) }\end{array}$ & $\begin{array}{l}\text { The lack of a 'single focus' } \\
\text { regional centre was reframed as } \\
\text { an opportunity rather than a } \\
\text { problem. }\end{array}$ \\
\hline 3. Transport infrastructure & $\begin{array}{l}\text { "You've only got to look at our } \\
\text { roads and rail and whatever, and } \\
\text { water supplies, and whatever. } \\
\text { There just doesn't seem to be } \\
\text { that long term vision." (Session } \\
\text { 2) }\end{array}$ & $\begin{array}{l}\text { Parallel road/rail routes through } \\
\text { region, linking towns, with fibre } \\
\text { broadband to follow route } \\
\text { reframed and envisaged as the } \\
\text { 'spine' of the linear city. }\end{array}$ \\
\hline $\begin{array}{l}\text { 4. Making Latrobe City concrete } \\
\text { and real }\end{array}$ & $\begin{array}{l}\text { "Latrobe City started, but, you } \\
\text { know, it was again something } \\
\text { funded by a government and } \\
\text { when the funds stopped the } \\
\text { initiative stopped." (Session } 3 \text { ) }\end{array}$ & $\begin{array}{l}\text { Building on reframing of issues } \\
1-3 \text {, issue } 4 \text { was reframed as the } \\
\text { opportunity of the linear Latrobe } \\
\text { City, 'pride of our nation and } \\
\text { internationally acclaimed'. } \\
\text { (Scenario 3, Dare to Dream) }\end{array}$ \\
\hline
\end{tabular}

Figure 2 - From participant generated problem issues to scenario team generated vision. 


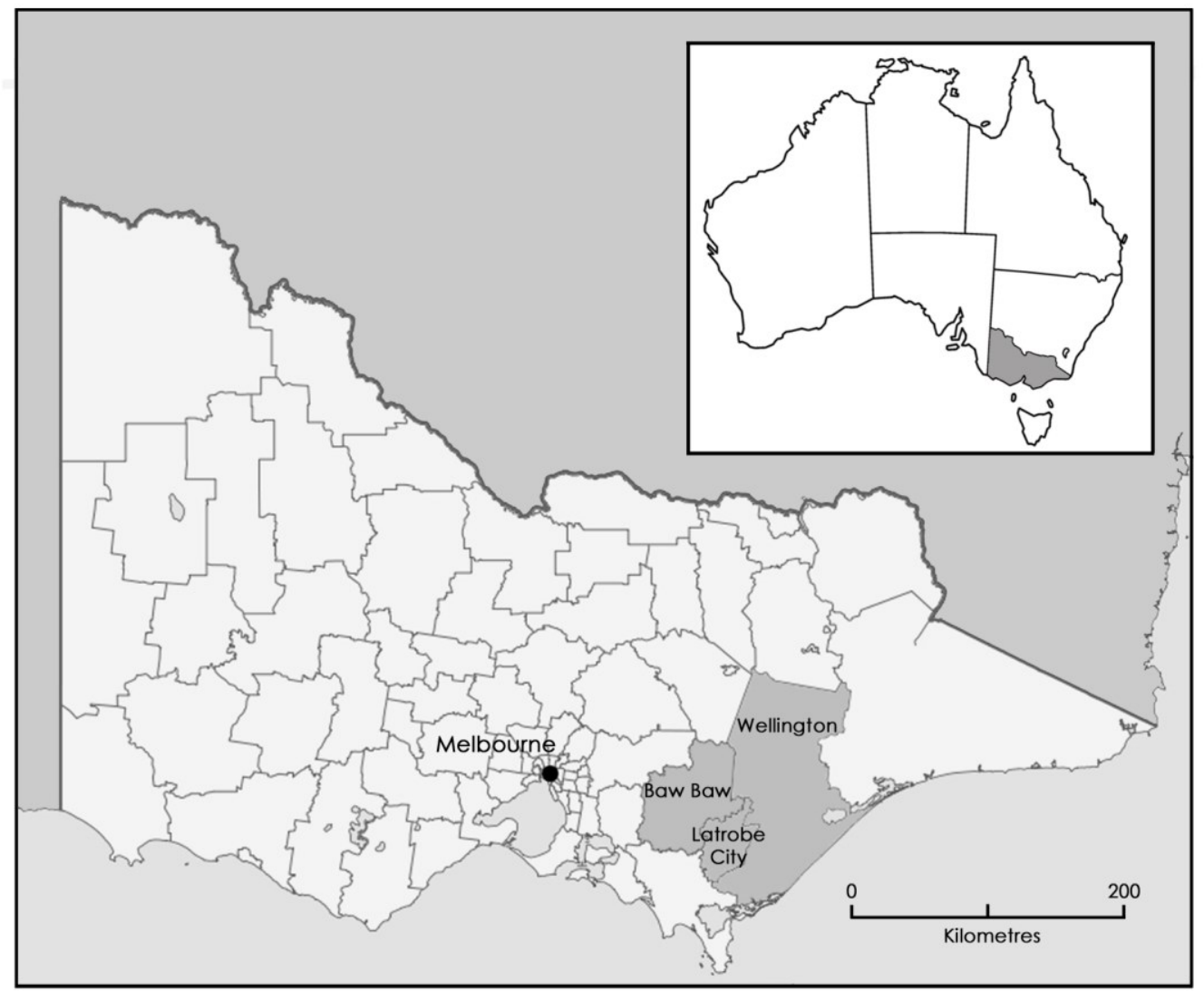

Map 1 - The Latrobe Valley Region, Victoria, Australia. 